\title{
Activity Theory to Investigate the Implementation of ICTE
}

\author{
Geoff Romeo and Ian Walker \\ Faculty of Education, Monash University, PO Box 527 Frankston 3199, Australia \\ geoff.romeo@education.monash.edu.au
}

Keywords: integration of ICT, primary, research, in-service training, management

\begin{abstract}
The purpose of this pilot study was to examine how one primary school implements Information and Communication Technologies in Education (ICTE). The principal, IT coordinator and two class teachers were interviewed to determine their views of how ICTE was being implemented. Activity theory was used as a means of analysing the data. The findings suggest a range of views about ICTE existed within the school. The implications suggest it is important for schools to recognise the different views of ICTE existing in their communities and to take cognisance of this when, for example, planning professional development. The study also suggests that more sensitive analytical approaches need to be developed to enable more critical evaluations of ICTE's implementation within schools to be made.
\end{abstract}

\section{INTRODUCTION}

Computers have been with us for just over fifty years and what has emerged in that time is a number of different, yet interrelated, perspectives on the use of information and communication technologies in education (Roblyer and Edwards 2000). Two of these perspectives in particular are worth highlighting in this discussion. The first perspective focuses on the computer as a mechanism by which to deliver information. This view is very much influenced by behaviourist learning theories and has led, for example, to the development of computer-assisted instruction (CAI), computer-based training (CBT) and technology training. The second and contrasting perspective focuses on the use of computers as a system to enhance teaching 
and learning. This view, often referred to as computers in education, very much influenced by the ideas of constructivism, is about exploiting technology's versatility and uniqueness to help the teacher establish powerful environments for children's learning across the curriculum. In the Australian context the latter view has tended to predominate, with the development of computer literacy and awareness as a subordinate objective. In most cases it is not until the latter years of high school that more formal information technology subjects are introduced.

During the 1990s significant events happened that further influenced how educators viewed the use of computers in the classroom. Two of these events in particular relate to Victorian schools. The first was the development of Intranets and the Internet, especially the World Wide Web (WWW), which allowed users to view multimedia via a browser such as Netscape or Internet Explorer. The second event was the commitment, by successive governments, to the development of technology in schools for administrative and curriculum purposes. This commitment has resulted in the expenditure of millions of dollars and the development of an astonishing array of projects and initiatives. This systemic commitment to the development of technology for administrative and curriculum purposes has had an enormous impact on schools. The use of computers in education or what is now more commonly referred to as information and communication technologies in education (ICTE) is now recognised as a critical aspect of a schools' teaching and learning program and consumes a considerable slice of a school's budget.

Increasingly, teachers, administrators, parents, education departments and governments are asking whether the return on the investment has been worthwhile. Searching for the answer to this question is difficult. The difficulty lies in how to judge the effectiveness of computer use in schools. A response to the question, favoured by some, is to count things (see for example the Department of Education, Employment and Training in Victoria 2000). But does this give a clear enough picture of what is actually happening in classrooms and does it reflect the reality of teacher attitudes towards the technology? For a deeper, more meaningful depiction of the current scene, further analysis is needed and powerful analytical tools must be employed. The purpose of this study was to investigate the potential of such a tool.

\section{ACTIVITY THEORY AS AN ANALYTICAL TOOL}

One way of understanding the introduction, development and maintenance of ICTE is to see it as a socially constructed practice in much the same way as researchers and practitioners view other educational 
concepts. The effect of seeing ICTE in this way is that it enables us to consider how those involved in the implementation process construe the activity. A way of doing this was to capture, through interviews, how those working in the same school viewed their own and others' positions relative to the development of ICTE.

We sought a theoretical perspective that would help us in our analysis of people's comments and, for this purpose, selected an approach that is referred to as activity theory. It is necessary to note that this choice was made to assist us in analysing the interview data we had planned to obtain rather than providing us with any meta-theory with explanative or predictive capabilities (see also Nardi 1996). In this way ICTE implementation in a school can be treated as a human endeavour that, in a Vygotskian sense, is mediated by social-cultural-historical tools and practices (Vygotsky 1978). The work of Engestrom in particular was taken as a useful means of applying the notion of activity theory to our investigation (see Engestrom et al. 1999, Engestrom 1993). Our choice of activity theory as an analytical device provides us with a holistic and systemic view of human engagement, in this case in ICTE implementation.

\section{METHODOLOGY}

The school used in this study is one of the largest government primary schools in the state of Victoria with over 800 pupils and 40 staff. This school was selected because of its reputation for innovative use of ICTE. On the surface it would appear to meet many of the criteria identified in, for example, EkinSmyth (1998) in order to determine effective ICTE implementation. We intended to seek volunteers to participate in this pilot study. The principal, however, selected three staff members: the current IT coordinator, a reluctant teacher, and a recent graduate, as well as himself to participate. Each interview, lasting approximately forty minutes, was audio taped.

\section{ANALYSIS}

The major elements of activity theory - subject, instruments, object and outcome, rules, community, and division of labour - were used to organise the interview data. This organisation was then used to identify major commonalities and contradictions amongst participants' perceptions of ICTE in their school. In order to preserve a sense of character in the analysis we present it in terms of how each participant saw ICTE being implemented. 
We summarise each participant's views in diagrams (after Engestrom 1987) accompanied by a brief discussion of the major aspects of how he or she constructs ICTE.

\subsection{Kevin: the principal}

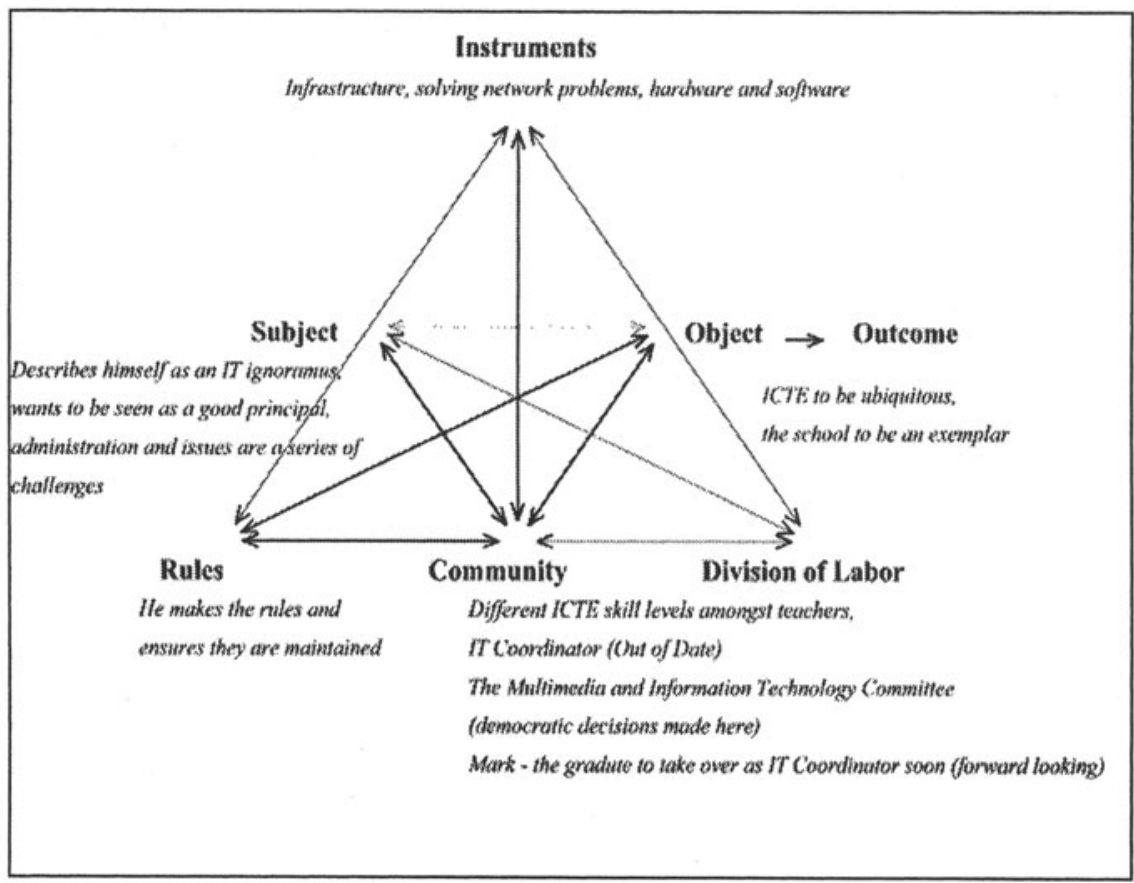

Figure 1. Kevin - The principal

Kevin is the inaugural principal of the school who describes himself as an "IT ignoramus". His comments about himself merge very quickly into how he saw the school's mission as essentially one of serving the wider community. The word "challenge" appears frequently in his description where, for example, the implementation of ICTE is seen merely as one of a number of competing challenges facing a principal of a large school. Kevin also frequently talks about these challenges in terms of how others, and in particular, the community, judge the school and, perhaps more importantly, himself.

The main object that Kevin identifies for ICTE is that it should be considered, among other things, as being embedded within normal classroom activities; " we don't see IT as a separate entity, we want it to be used right through the eight KLAs" [Key Learning Areas]. For Kevin the ideal 
classroom is one where the teacher "is flexible enough to work on many different things [including IT activities] at any given time, so the computers in the room would be ticking away...". To achieve this object Kevin, despite obviously being aware of computer software and the notion of computers being integrated across the curriculum, focuses on getting the infrastructure and related hardware working. This is illustrated, for example, in his final words about the school's intranet.

"...not working all the time (and) I've got to get the technician to a point where the whole thing is compatible and it works... once these problems are solved and this new magic, super duper file server is in place, if we can speed up the system...then that's terrific, so that's what we want, ease of use...but from an administrative point of view it doesn't work as well as 300,000 dollars worth of equipment should work, by my way of thinking".

Given that it would appear the school was misled a number of years ago about appropriate network architecture for its computers, the emphasis by the principal on infrastructure difficulties is not surprising.

When asked about the members of the school community who were involved with ICTE, Kevin highlights, as did all participants, the different level of ICTE skills held by teachers including some of the key players. He provides this, along with infrastructure difficulties, as an explanation of why ICTE has not gone as far as it might have in the school. As far as the principal is concerned, for example, the current IT coordinator is out-of-date, the graduate teacher is more au fait with current technology and in a better position to move ICTE in the school forward.

Another community element recognised by all participants in the implementation of ICTE is the Multimedia Information and Technology Committee (MMIT). Listening to Kevin one would think that this committee provides a democratic opportunity for staff to be involved in the decisionmaking processes regarding ICTE. Subsequent interviews suggest that others do not share this view.

The rules by which an organisation such as a school goes about its work is a further revealing feature of an analysis based on activity theory. It is in the principal's comments about the roles and responsibilities of his staff in terms of ICTE that insight into the rules governing work in the school become most apparent. As with other issues facing the school, the development of ICTE is very much under the control of one person - the principal. Kevin, for example, comments: "I sort of insist on software being purchased across the various KLAs and at the moment I've got the brakes on the system". The other participants reinforce this view of the principal's control over the school's activity in ICTE, and other areas. 


\subsection{Peg: the reluctant teacher}

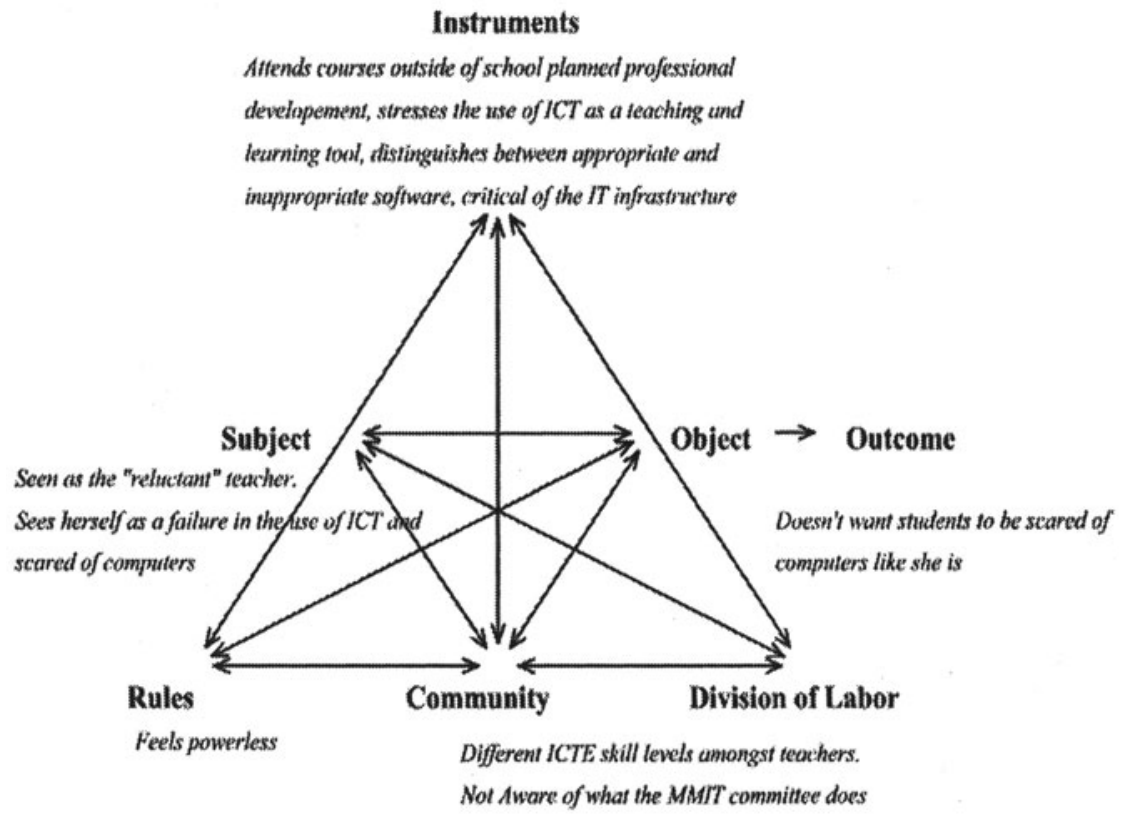

Figure 2. Peg - The 'reluctant' teacher

Early in her interview Peg, a current year 4 teacher, remarks that the principal had construed her as "the reluctant staff member". As the interview progressed, however, it becomes apparent that this is an incorrect assessment. Peg consistently describes herself as being "basically scared of computers", something she traces to a lack of the technology in her background. However what emerges is that this fear, rather than acting as a deterrent to her engaging with computers, acts as a very strong motivator. It accounts for her pursuit of knowledge about information technology through attendance at a number of short courses offered by both private companies and TAFE (Technical and Further Education) colleges; something one is not likely to find in a reluctant teacher. What is particularly significant here is that Peg chooses to go outside of the school and its professional development agenda to gain this experience. Peg's declared fear of computers also leads her to be especially cognisant of the needs of the children she teaches. For example:

"I think I'm basically scared of computers and because I'm scared of them I don't want them [the children] to be like that because they are 
going to be much more into the use of computer technology in their lives than what I am".

In terms of the mediating instruments on which Peg focuses her comments, there is an interesting contrast between these and comments made by both the principal and the IT coordinator. Whereas these two participants highlight the infrastructure in the development of ICTE, Peg stresses the use of technology as a tool for teaching and learning. This represents an important difference in how participants think about ICTE: whether the focus is on the technology itself or on its application in a teaching and learning environment. Peg, for example, acknowledges the need for professional development but considers that what the school currently offers is not related to teaching and learning and not sufficiently practical. Peg also believes that much of the software used by children is inappropriate in that it does not enable them to easily obtain information for specific projects. Clearly Peg is judging the instruments in this activity differently to the principal (and to the IT coordinator).

The interview shows Peg to be someone who is easily frustrated by what appears to be an unstable infrastructure. She is repeatedly critical of the system: "our computer lab is less than efficient and often the computers don't work or one half works and the other half doesn't work, so it becomes a very frustrating exercise". It may well be these criticisms that lead Kevin, who wants his school to be judged as successful, to see her as 'reluctant'.

This interview reveals much of the complexity of how individuals see themselves and others in relation to developments, such as ICTE, occurring within their school. 


\subsection{John: the IT coordinator}

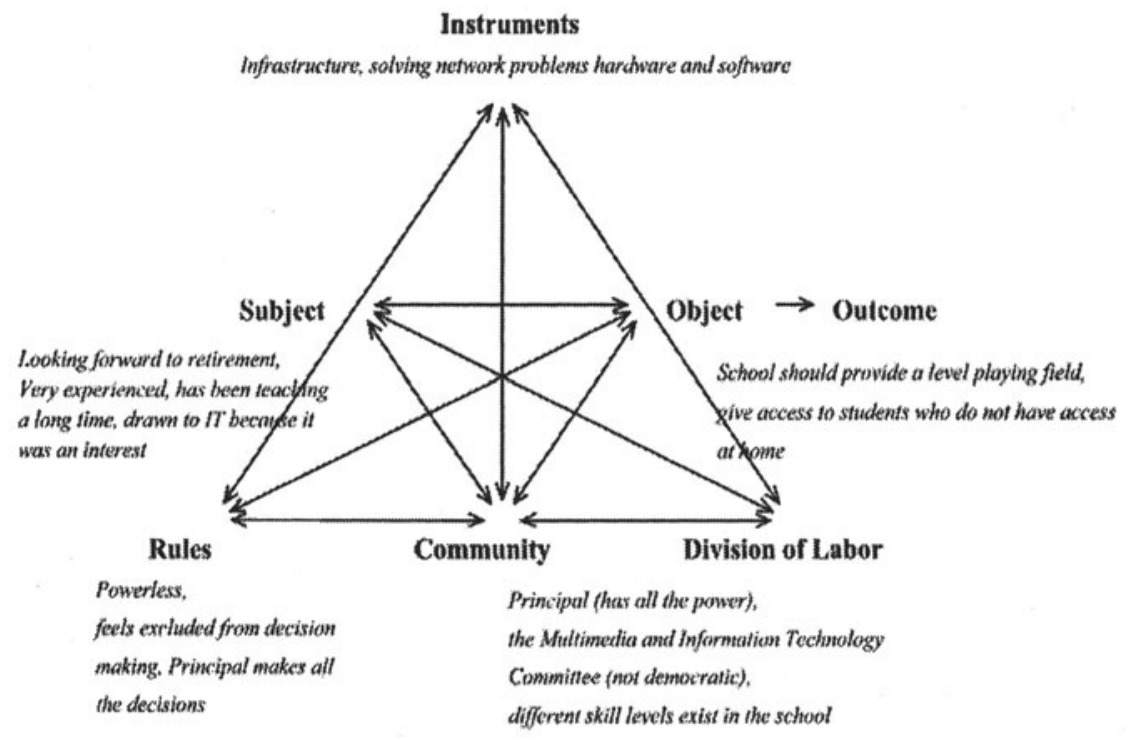

Figure 3. John - The IT coordinator

John, who has been teaching for over 30 years and is looking forward to his retirement next year, is the IT coordinator at the school. His role in this position is seemingly one based on "just an interest that I have picked up" and John has not considered it necessary to pursue formal qualifications specific to ICTE. Whereas Peg saw the importance of ICTE as ensuring that children feel unthreatened by computers, John sees ICTE more in terms of creating a level playing field so that children without computer access at home are not disadvantaged.

Like the principal, John focuses much of his discussion on the infrastructure in the school highlighting the fact that it is not working efficiently. Throughout John's interview there appears to be a note of disenchantment with many aspects of ICTE in the school and a feeling of helplessness in terms of his involvement in the decision-making process. John, for example, cites the MMIT committee as a means by which the administration establishes what appears to be a democratic process on the one hand, while effectively controlling the important decisions on the other. $\mathrm{He}$ is keen to pass blame for the system not working, therefore, to a principal who is keen to control, but who "really doesn't understand computers and doesn't use them". 
Although John is the designated IT coordinator it would seem that many decisions about computers are being made by the principal, without his input. We picked up a sense that both John and, indeed, the principal are waiting for John's retirement. In fact, during our interview with the principal, it was clear that he had already decided on John's replacement - Mark, "a promising young teacher".

\subsection{Mark: the recent graduate}

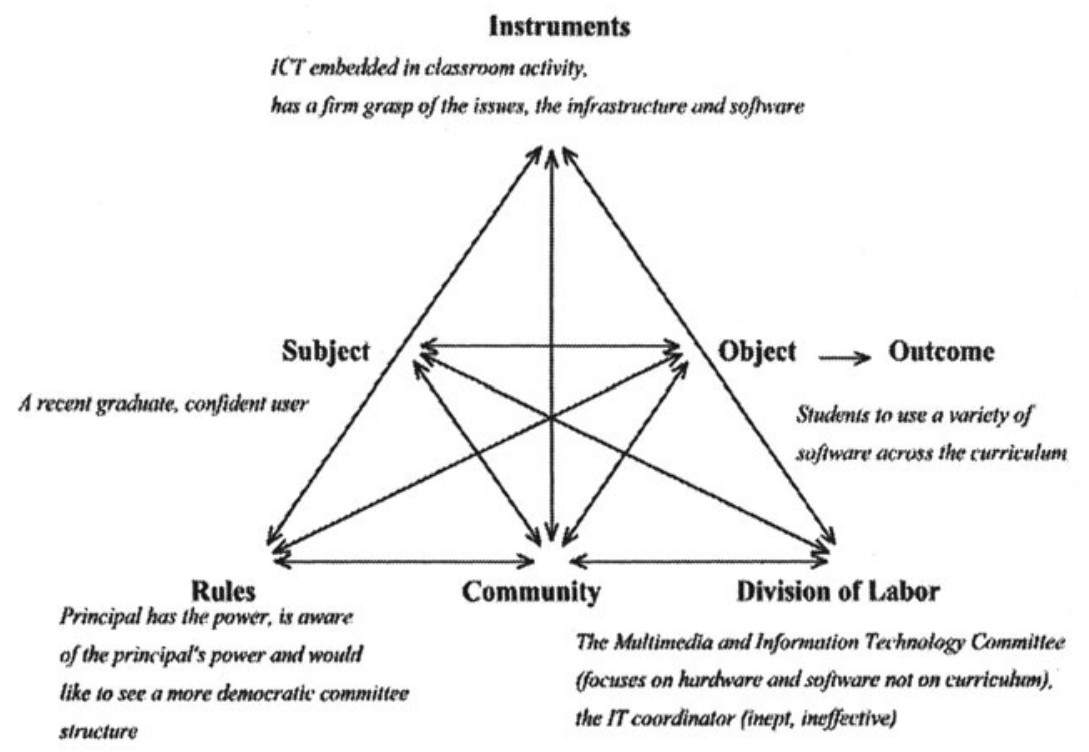

Figure 4. Mark - The recent graduate

Mark is a recent graduate who has been teaching at the school for over two years. He is currently teaching children in their first year of schooling. Unlike Peg, Mark has no fear of computers. He has not completed any formal courses in information technology; other than as components of his journalism and teaching qualifications, but computers have always been a part of his life. "In primary school we had the old Commodore 64s and...I've never been afraid of them and I know where they're coming from in a lot of ways". Like Peg, Mark sees ICTE best being embedded within classroom activities thereby enabling children to use it for a variety of purposes across the curriculum. For these reasons Mark is happy to experiment with new software. At the same time he believes he has a grasp of the infrastructure and hardware issues in the school and feels confident in talking about them. 
During a discussion of the MMIT committee Mark's comments resonate with those made by both Peg and John regarding this committee's focus on hardware. He also talks about the lack of genuine engagement many teachers like Peg have with the committee. Whereas John attributes this lack of engagement to the principal's control and lack of knowledge, Mark sees the disengagement more in terms of the fact that the committee focuses on the wrong issues: "...a lot of the meeting is devoted to the technology that is coming in or the hardware rather than the programs that are being done...a lot of teachers don't know enough about the hardware".

\section{CONCLUSIONS}

From the analysis it is clear that there is not a shared vision about how ICTE should be implemented in the school used in the study. For Kevin and John the focus of their thinking is extensively about cables, servers and boxes on desks. For Peg and, to a lesser extent Mark, it is about teaching and learning. As the four people interviewed for this project are key players in the implementation of ICTE in this school, one could assume that the lack of a shared vision is indicative of the staff's mindset. This lack of a shared view of what ICTE should be is problematic: without consensus on the key issues stagnation and waste are likely and, according to Kevin, a reality - "we haven't got our 300000 dollars worth".

The two major factors impeding the development of a shared vision about ICTE for this school are: the decision-making process and, how this in turn is tied to ownership of ICTE and its implementation. It is worth briefly examining each of these factors.

Throughout each interview, the principal's effective control of all of the school's activities, including ICTE, is apparent. Although it is understandable that a school principal takes ultimate responsibility for these activities, in many schools and in many areas of activity such responsibility is delegated to other members of the school community. In the case of ICTE in this school, however, it would seem that the delegation is superficial and the principal effectively maintains complete control of the important decisions that need to be made regarding its implementation. There is, for example, a designated IT coordinator and a committee (MMIT) seemingly established to encourage communication among teachers regarding decisions about ICTE. However, it is clearly the principal who controls the MMIT committee and has managed to marginalise the current IT coordinator by denying him serious budgetary responsibility, a point reinforced by Mark.

The strength of the principal's control over the decision-making process contributes to a lack of shared ownership of the ICTE process in the school. 
For John this results in cynicism, resentment and resignation. For Peg it results in disengagement and for Mark in opportunity. It would seem that the machinations of the MMIT committee also contribute to a sense of alienation. Teachers like Peg are disenfranchised from the workings and discussions of the MMIT; they do not know what the committee discusses, what its role is, they never get any feedback about its decisions and they are not asked to contribute to the committee's deliberations.

\section{IMPLICATIONS}

A number of implications emerge from this pilot study. First, in an attempt to appreciate how a school goes about implementing policies such as ICTE, it is useful to locate the implementation within the broader milieu of the school and, in particular, the way decisions are made. Second, it is important for schools to recognise and cater for the range of views of ICTE held by members of its community. As there is a variety of ways teachers, for example, construct information technology and its relation to children's learning, it is necessary, for effective implementation to occur, to know what these constructions highlight - whether, for example, is it computer infrastructure or its application to teaching and learning that most interests individuals. Schools need to consider the different constructions of ICTE when planning effective professional development activities.

Thirdly, the criteria commonly used to evaluate the level of ICTE implementation taking place within a school need to be developed, so that they become more sensitive to the subtleties of policy and program implementation and to people's attitudes towards it. Our pilot study, for instance, shows that although one school would satisfy a number of indicators suggested in the literature as a means of determining the extent to which ICTE is being effectively implemented, closer examination reveals greater complexity and contradiction.

Finally, it has been stated throughout this paper that this was a pilot study. We have found both the means of obtaining data and its analysis used in the study to be valuable in uncovering something of the richness of life in a school: in this case, the implementation of ICTE. We recommend, therefore, that larger studies be undertaken in a variety of educational settings to obtain a greater sense of how different schools are implementing ICTE and the factors that account for its success or failure. 


\section{REFERENCES}

Department of Employment, Education and Training, Victoria (2000) Learning Technologies Projects, Products and Services. [http://www.sofweb.vic.edu.au/itb/]16.10.00.

(DEET) Department of Employment, Education and Training (1988) Teachers Learning: Improving Australian Schools Through Inservice Teacher Training and Development. Australian Government Publishing Service, Canberra, Australia.

EkinSmyth, C. (ed) (1998) Rethinking Learning and Teaching: The Navigator Schools' Experience. Report 1, July 1998, Melbourne, Community Information Service, Department of Education, Victoria.

Engestrom, Y. et al. (1999) Perspectives on Activity Theory. Cambridge, UK, Cambridge University Press.

Engestrom, Y. (1993) Developmental Studies of Work as a Test Bench of Activity Theory: The case of primary medical care practice. In Understanding Practice, S. Chaiklin and J. Lave (eds.), Cambridge, UK, Cambridge University Press.

Engestrom, Y. (1987) Learning by Expanding: An Activity-Theoretical Approach to developmental Research, Helsinki, Orieta-Konsultit.

Fullan, M. and Hargreaves, A. (1990) What's Worth Fighting For? Working Together For Your School. Australian Council for Educational Administration Inc. Hawthorn, Victoria, Australia.

Nardi, B. (1996) Context and Consciousness: Activity Theory and Human-Computer Interaction. Cambridge, Massachusetts, MIT Press.

Roblyer, M. D. and Edwands J. (2000) Integrating educational technology into teaching. Upper Saddle River, N. J. Merrill.

Vygotsky, L. (1978) Mind in Society: The Development of Higher Psychological Processes. Cambridge, Massachusetts, Harvard University Press.

\section{BIOGRAPHY}

Geoff Romeo and Ian Walker are teacher educators and researchers working at Monash University. Dr Walker's research interests include parental involvement; children's literacy; literacy practices in the workplace; teaching practicum and more recently the use of technology in schools. Dr Romeo's research interests include the use of information and communication technology in education to improve teaching and learning, the development of primary curriculum, action research and primary education in general. Dr Romeo is president of the Computing in Education Group of Victoria and a board member of the Australian Council for Computers in Education. 